\title{
Gestão De Capital De Giro Líquido E De Fluxo De Caixa Em Risco De Empresas De Bens Industriais Listadas Na Bmf\& Bovespa
}

\author{
Management Of Working Capital And Cashflow At Risk For Indutrial Goods Companies \\ Listed In Bmf\&Bovespa
}

\author{
Abdinardo Moreira Barreto de Oliveira \\ abdinardo.oliveira@univasf.edu.br \\ UNIVASF
}

\author{
Rodrigo de Oliveira Ramalho \\ Rodrigopiru_@hotmail.com \\ UFC
}

\author{
André Aroldo Freitas de Moura \\ andrearoldo2@hotmail.com \\ UFC
}

\begin{abstract}
Resumo: O objetivo deste estudo foi avaliar o desempenho de empresas brasileiras de bens industriais quanto à gestão de capital de giro líquido e quanto à capacidade de geração de caixa em risco, haja vista que estas temáticas estão intrinsecamente associadas e que seu bom gerenciamento é condição necessária para a manutenção da sustentabilidade financeira organizacional. Neste intuito, foi realizado um levantamento com nove empresas listadas na BMF\&BOVESPA, dentre uma população de 16 companhias. Foram coletados 47 relatórios contábeis trimestrais por empresa entre 1999 e 2010, onde os dados foram formatados de acordo com as orientações de Fleuriet, Kehdy e Blanc (2003) e do método indireto de fluxo de caixa (GITMAN, 2004). A análise dos dados procedeu-se através de estatística descritiva, teste não-paramétrico Kruskal-Wallis, regressão linear e simulação de Monte Carlo para o cálculo do risco. Quanto à gestão do capital de giro líquido, foi verificado que as empresas possuem dificuldades para financiar e gerenciar seu capital de giro líquido, cujas chances de solvência são de $17 \%$, de inadimplência são $51 \%$ e de insolvência são de $32 \%$. Quanto à gestão de caixa, a maioria das empresas têm chances superiores a $50 \%$ de terem fluxos de caixa positivos, ainda que o risco da não ocorrência esteja entre $34 \%$ e $50 \%$. Comentários adicionais estão no final do artigo.
\end{abstract}

Palavras-chave: Capital de giro líquido; Fluxo de caixa; Bens industriais; Gestão de risco.

Abstract: The aim of this paper was to evaluate the performance of Brazilian industrial goods companies on the management of working capital and for their ability to generate cash flow at risk, given that these issues are inextricably linked and its good management is a necessary condition for maintaining financial sustainability organizational. To this end, it was performed a survey with nine companies listed on BMF\&BOVESPA, among a population of 16 companies. They were collected 47 reports quarterly statements by company between 1999 and 2010, when data were formatted in accordance with the guidelines of Fleuriet, Kehdy e Blanc (2003) and the indirect method of cash flow (GITMAN, 2004). Data analysis proceeded with descriptive statistics, Kruskal-Wallis nonparametric test, linear regression and Monte Carlo simulation to calculate the risk. For management of working capital, it was found that all companies have difficulties to finance and manage their working capital, whose chance of solvency is $17 \%$, chance of default is $51 \%$ and chance of insolvency is $32 \%$. For cash flow management, although most of companies have more than $50 \%$ chance of having 
positive cash flows, the risk of non-occurrence of these is between $34 \%$ and $50 \%$. Additional comments are at the end of this paper.

Keywords: Working capital; Cash flow; Industrial goods; Risk management.

Artigo recebido em: 05.02.2013; Aceito em: 30.04.2013

\section{INTRODUÇÃO}

$\mathrm{O}$ aspecto da sustentabilidade financeira das empresas brasileiras continua sendo importante tema de estudo para os pesquisadores e um desafio para novos empreendedores que desejam prosperar suas organizações. Neste intuito, há duas diretrizes a serem consideradas que são (1) a gestão de capital de giro líquido e (2) a gestão de fluxo de caixa, as quais estão indubitavelmente interligadas por sua natureza.

O gerenciamento do capital de giro líquido é apontado com o suporte de todo o negócio financeiro e, segundo Moura e Matos (2003), a sua má gestão pode comprometer as atividades operacionais de curto prazo, prejudicando seu ciclo operacional e a sua capacidade de geração de caixa que, por conseguinte, afetaria negativamente a maximização do valor da companhia. Além disto, há de se considerar os riscos de mercado que afetam certos setores, como as variações nas taxas de juros, no câmbio, no preço das commodities, na demanda dos consumidores e na oferta de matérias-primas e insumos para a produção, haja vista que eles também podem afetar a liquidez (capital de giro líquido) e a capacidade financeira (fluxo de caixa) das empresas (ALBUQUERQUE, PEROBELLI; CASTRO, 2009).

Ainda neste aspecto, os estudos sobre gestão de capital de giro líquido e de fluxo de caixa, específicos para empresas não-financeiras, ainda são incipientes, principalmente quando é levado em consideração o componente risco em seu gerenciamento. De acordo com Albuquerque, Perobelli e Castro (2009), embora a modelagem de risco de mercado encontrese bem avançada no setor financeiro, o seu uso ainda é pequeno nas instituições nãofinanceiras, talvez pela dificuldade de se adequar os conceitos vindos do mercado financeiro para o cotidiano das empresas. Em sua maioria, a análise da sensibilidade dos fatores de risco está desconectada das variáveis macroeconômicas e de até outras variáveis importantes tanto para o capital de giro líquido como para o fluxo de caixa.

Neste sentido, o foco deste trabalho será as empresas de bens industriais listadas na BMF\&BOVESPA, o qual tem uma participação importante na economia brasileira. De acordo com a Associação Brasileira da Indústria de Máquinas e Equipamentos (ABIMAQ, 2010), no período 2006-2010, as empresas do setor apresentaram um crescimento no faturamento bruto nominal de $33,1 \%$ (de $\mathrm{R} \$ 54,71$ para $\mathrm{R} \$ 72,79$ bilhões), um aumento nas exportações de $6,0 \%$ (de US\$ 8,74 para US\$ 9,26 bilhões) e um incremento de $21,0 \%$ no número de pessoal ocupado (de 207.828 para 251.567 trabalhadores). Neste aspecto, é importante ressaltar que estes valores só não foram melhores por causa da crise financeira mundial ocorrida em 2008.

Apesar dos resultados acima citados, a Abimaq (2008) ainda aponta algumas dificuldades relevantes para o setor, como o (1) crescimento abaixo da média mundial, (2) o crescimento da importação de bens de capital, (3) a falta de isonomia tributária, (4) as taxas de juros elevadas e (5) a baixa oferta de linhas de financiamento. Estes fatores podem afetar a competitividade das empresas de bens industriais frente aos concorrentes estrangeiros. Por exemplo, em termos de importações de máquinas e equipamentos entre 2006 e 2010, este teve um crescimento de $127,0 \%$ (de US\$ 11 para US\$ 25 bilhões), o gerou um déficit acumulado 
de US\$ 43 bilhões, principalmente graças aos países asiáticos. Tais efeitos combinados podem estar afetando a qualidade da gestão do capital de giro líquido e da capacidade de geração de caixa destas empresas, podendo comprometer a sua sustentabilidade a longo prazo. Diante dos fatos acima mencionados, o objetivo deste estudo será analisar a qualidade da gestão do capital de giro líquido e do fluxo de caixa em risco das empresas de bens industriais listadas na BMF\&BOVESPA e, desse modo, poder contribuir para o desenvolvimento de metodologias que possam apontar indícios de sustentabilidade financeira.

\section{REFERENCIAL TEÓRICO}

\subsection{Aspectos teóricos sobre a gestão de capital de giro líquido}

O conceito de capital de giro líquido (ou capital circulante líquido) enfatiza a captação e o uso de recursos monetários de longo prazo para a realização de investimentos em ativos de curto prazo que, através da atividade empresarial, poderão ser convertidos novamente em recursos monetários disponíveis no prazo de até um ano, imprescindíveis para a sustentabilidade de todo o ciclo operacional e financeiro das empresas ao longo dos anos (OLIVEIRA, 1996; SOUZA; MENEZES, 1997; BRIGHAM; HOUSTON, 1999).

Neste ínterim, a identificação do volume de recursos monetários em capital de giro líquido necessários para o funcionamento das atividades de curto prazo de uma empresa se dá pela equação $\mathrm{CCL}=\mathrm{AC}-\mathrm{PC}$, onde CCL representa o Capital Circulante Líquido, $\mathrm{AC}$ representa o Ativo Circulante (investimentos de curto prazo) e PC representa o Passivo circulante (financiamentos de curto prazo). Através dela, é possível observar se a organização possui algum "alívio" financeiro no seu ciclo operacional, que poderá ser utilizado para refinanciar todo seu processo produtivo. Caso o CCL > 0, significa que a empresa consegue honrar suas obrigações de curto prazo e produzir um excedente de recursos monetários. Se o CCL $=0$ significa que toda a riqueza monetária produzida foi integralmente utilizada para saldar seus compromissos com os credores a curto prazo. Mas se o CCL < 0 , representa que a companhia não consegue honrar completamente suas obrigações de curto prazo, exaurindo toda a fonte de financiamento de suas atividades operacionais.

A partir destas interpretações, o resultado que uma gestão efetiva do CCL traz para a saúde financeira de uma organização é a sua liquidez, seja no curto ou no longo prazo. Entende-se por liquidez a capacidade de poder pagar seus compromissos financeiros na data do vencimento, o que contribui para a solvência da gestão do CCL. Do contrário, a companhia terá uma gestão de CCL inadimplente ou insolvente (ASSAF NETO; SILVA, 2002; GITMAN, 2004; HOJI, 2004).

Embora seja um simples instrumento para o gerenciamento do CCL, a técnica supracitada apresenta a seguinte limitação: mostra somente a eficácia do processo de gestão do CCL, ignorando o aspecto da eficiência, que é a adequada distribuição dos recursos monetários entre os investimentos de curto prazo - Disponibilidades, Créditos e Estoques. Para contribuir com uma análise mais precisa da gestão do CCL nas organizações, Michel Fleuriet, a partir de investigações em empresas brasileiras realizadas na década de 1980, apresentou uma abordagem dinâmica para a administração do capital de giro líquido (BRASIL; BRASIL, 1997). A análise dinâmica do capital de giro líquido apresenta duas novas variáveis que complementam a análise clássica, permitindo uma melhor compreensão da composição e gestão do CCL nas organizações: a Necessidade de Investimento em Giro (NIG) e o Saldo em Tesouraria (ST). Para se obter os valores destas variáveis, é preciso primeiro fazer uma reclassificação das contas contábeis presentes no Balanço Patrimonial em três tipos: Estratégicas, Operacionais e Táticas. 
As contas de natureza Estratégica abrangem as contas cuja movimentação está vinculada à alta administração da empresa. Por exemplo, o nível de capacidade de produção esperada dependerá do investimento fixo a ser empregado na organização, o que implica saber como esse investimento será financiado - através de recursos próprios ou por financiamento de terceiros. A equação que define esta relação é: $\mathrm{CCL}=(\mathrm{PL}+\mathrm{PELP})-(\mathrm{ARLP}+\mathrm{AP})$ Esta nova abordagem permite realizar a gestão do Capital de giro líquido a partir da perspectiva da existência de fontes de financiamento permanentes de longo prazo suficientes para financiar os investimentos fixos e de giro.

As contas de natureza Operacional correlacionam-se com a atividade (o negócio) da empresa. Decisões que envolvem o volume de estoque, vendas à vista ou a prazo, compras à vista ou a prazo, salários e impostos são exemplos destas questões. A equação que explica esta relação é: $\mathrm{NIG}=\mathrm{AO}-\mathrm{PO}$, onde AO significa Ativo operacional, que são os investimentos de curto prazo diretamente relacionados com o negócio da empresa; e PO significa Passivo operacional, que são os financiamentos não-onerosos diretamente relacionados com as atividades da empresa. É importante também mostrar a relação que a NIG apresenta com o Ciclo Financeiro ( $\mathrm{CF}=$ NIG/Receita Bruta*360) da companhia. Quando as saídas de caixa ocorrem antes das entradas de caixa, é gerada uma necessidade de capital de giro líquido positiva, demandando uma aplicação operacional líquida de recursos monetários. Caso aconteça o oposto - as entradas de caixa acontecer antes das saídas de caixa - é gerada uma necessidade de capital de giro líquido negativa, o que indica a existência de uma fonte operacional líquida de recursos monetários.

Por fim, as contas de natureza Tática representam as contas de curto e curtíssimo prazo, em geral administradas pela tesouraria das empresas. Aspectos referentes às manutenções de um volume de caixa mínimo, aplicações de curto prazo no mercado financeiro visando à manutenção do poder de compra do dinheiro, captação de empréstimos para pagamento da folha de pessoal da empresa, dentre outros, são exemplos de decisões táticas. A equação que determina esta relação é: $\mathrm{ST}=\mathrm{AF}-\mathrm{PF}$, onde $\mathrm{AF}$ representa o Ativo financeiro, que são os investimentos financeiros de curto prazo efetuados pela organização, e PF representa o Passivo financeiro, que são os financiamentos onerosos de curto prazo obtidos pela companhia. Desse modo, procura-se definir as contas ativas e passivas em função da realidade dinâmica das empresas, onde as contas relacionam-se aos ciclos operacionais e financeiros da organização, que lhes atribui um estado de permanente movimentação (FLEURIET; KEHDY; BLANC, 2003; VIEIRA, 2005).

Tomando como referência a reclassificação contábil sugerida pela análise dinâmica do capital de giro líquido, Marques e Braga (1995) relacionaram as três variáveis dinâmicas (CCL, NIG e ST) em seis possíveis estruturas (com suas respectivas situações) que uma organização poderá apresentar na sua gestão de Capital de giro líquido. Como contribuição à metodologia, Theiss Júnior e Wilhelm (2000) desenvolveram uma escala de notas com o intuito de medir o desempenho que a empresa obteve em cada situação prevista, conforme mostra o Quadro 1.

\begin{tabular}{|c|c|c|c|c|c|}
\hline Estrutura & CCL & NIG & ST & Situação & Notas \\
\hline I & + & - & + & Excelente & 8,33 a 10,00 \\
II & + & + & + & Sólida & 6,67 a 8,32 \\
III & - & - & + & Alto Risco & 5,00 a 6,66 \\
IV & + & + & - & Insatisfatória & 3,33 a 4,99 \\
V & - & - & - & Muito ruim & 1,67 a 3,32 \\
VI & - & + & - & Péssima & 0,00 a 1,66 \\
\hline
\end{tabular}

Quadro 1 - Tipos de estruturas financeiras e respectivas notas

Fonte: Adaptado de Marques e Braga (1995) e Theiss Júnior e Wilhelm (2000). 
Com estas estruturas, é possível compreender melhor o fenômeno do overtrading, também conhecido como "Efeito Tesoura", que acontece toda vez que o valor da NIG ultrapassar o valor do CCL. Isto significa que os gastos para se manter as operações da empresa são maiores que os recursos monetários que ela dispõe para financiá-los, comprometendo seu ST para futuros investimentos da atividade produtiva (MARQUES; BRAGA, 1995; FLEURIET; KEHDY; BLANC, 2003; VIEIRA, 2005).

Assim, as estruturas III a VI culminam em situações que são exemplos de "Efeito Tesoura" que a companhia pode apresentar, sendo a situação VI a pior delas. A estrutura III também aponta um exemplo de Efeito Tesoura, só que para valores negativos de CCL e NIG. Logo, a meta de qualquer gestor financeiro é posicionar sua empresa na situação I ou II, sob pena de erodir suas reservas financeiras e conduzi-la ou à inadimplência ou à insolvência.

Sobre este assunto Famá e Grava (2000) fazem a seguinte distinção. O processo de inadimplência ocorre quando existe uma assincronia entre os prazos de recebimento e de pagamento da empresa, ou seja, a companhia possui os recursos financeiros para quitar a dívida, porém num prazo posterior ao do seu vencimento. Já a insolvência se caracteriza pela indisponibilidade de recursos financeiros para quitar suas obrigações. Assim, a inadimplência se torna o primeiro passo em direção a uma situação de insolvência. Com esta nova abordagem, as estruturas apresentadas no Quadro 01 ganham também a seguinte interpretação: os exemplos (I) e (II) indicam que a empresa está com solvência; os exemplos (III) e (IV) indicam que a empresa está com inadimplência e os exemplos (V) e (VI) indicam que a empresa está com insolvência (OLIVEIRA; SILVA; SILVA, 2006).

Caso aconteça um "efeito tesoura" na gestão do capital de giro líquido de uma empresa, seu gestor deve observar a existência dos seguintes fatos na instituição, para poder desenvolver planos de ação efetivos que revertam esta situação: (1) excesso de investimentos ligados à escassez de recursos próprios ou de terceiros de longo prazo; (2) possuir elevado ciclo financeiro; (3) baixa geração de lucros ou prejuízo nas operações; (4) a combinação das três situações anteriores, aumentando a diferença ente a NIG e o CCL (SILVA, 2001).

\subsection{Importância da elaboração de fluxos de caixa}

A capacidade de geração de caixa é um dos assuntos que demandam uma maior atenção por parte dos gestores financeiros das empresas, seja para o planejamento e organização das finanças de curto prazo, seja para a definição e execução de estratégias focadas para a criação de valor para seus proprietários. Neste quesito, um relatório contábil ganha relevância no auxílio dos administradores financeiros nesta tarefa, que é a Demonstração do Fluxo de Caixa (DFC).

Sendo relatório exigido no Brasil desde a promulgação da Lei n. ${ }^{\circ}$ 11.638/07, que alterou a Lei n. ${ }^{\circ}$ 6.404/76, ela é de grande importância porque consegue demonstrar para o gestor a sua disponibilidade monetária, cujo resultado é decorrente das movimentações de numerário provocadas pelas necessidades de reinvestimento da empresa em (i) gastos líquidos de capital, referentes às variações ocorridas nos ativos não-circulantes (Realizável a Longo Prazo e Permanente), e de (ii) investimentos em capital de giro líquido, decorrentes das peculiaridades de produção e venda que afetam os ativos e passivos circulantes de cada companhia.

\begin{tabular}{|l|l|l|}
\hline \multicolumn{1}{|c|}{ OPERACIONAIS } & \multicolumn{1}{|c|}{ INVESTIMENTOS } & \multicolumn{1}{c|}{ FINANCIAMENTOS } \\
\hline$\Delta$ Lucro Líquido & $\Delta$ Realizável a Longo Prazo & $\Delta$ Empréstimos de curto prazo \\
(+) Depreciação & $\Delta$ Investimentos & $\Delta$ Debêntures \\
$\Delta$ Créditos & $\Delta$ Imobilizado & $\Delta$ Dívidas com pessoas ligadas
\end{tabular}




\begin{tabular}{|l|l|l|}
$\Delta$ Estoques & $\Delta$ Intangível & $\Delta$ Dividendos a pagar \\
$\Delta$ Outros ativos circulantes & $\Delta$ Diferido & $\Delta$ Exigível a Longo Prazo \\
$\Delta$ Fornecedores & $\Delta$ Capital Social \\
$\Delta$ Impostos & $\Delta$ Reservas de Capital \\
$\Delta$ Provisões & $\Delta$ Reservas de Lucro \\
$\Delta$ Outros passivos circulantes & & $( \pm)$ Ajustes de lucros \\
\hline
\end{tabular}

Quadro 2 - Modelo da Demonstração do Fluxo de Caixa, método indireto

Fonte: Adaptado da BMF\&BOVESPA e GITMAN (2004).

A estrutura da DFC empresarial é resultado da formatação de três fluxos: (1) os relacionados às atividades operacionais [FCO], (2) os relacionados às atividades de investimento [FCI] e (3) os relacionados às atividades de financiamento [FCF]. A soma destes fluxos produz o Fluxo de Caixa [FC], que é a "principal matéria-prima para estimar o valor de uma empresa, medir a rentabilidade de um projeto de investimento, planejar as operações ou estabelecer a capacidade de pagamento de uma dívida" (SAMANEZ, 2007, p.71).

O Quadro 2 ilustra a composição de cada um dos fluxos citados, através do método indireto, bem como a influência de cada conta contábil na sua composição, às quais foram adaptadas de acordo com o formato dos relatórios contábeis publicados na BMF\&BOVESPA para empresas não-financeiras. Assim, o gestor financeiro poderá executar uma das etapas do planejamento financeiro, que é a elaboração do Orçamento de Caixa, cujo objetivo é estimar futuras necessidades de caixa no curto prazo, com dedicação especial para projetos de uso de superávits e a cobertura de déficits (GITMAN, 2004).

\section{METODOLOGIA}

O presente estudo foi realizado no intuito de verificar como ocorreu a gestão de capital de giro líquido e a capacidade de geração de caixa de empresas de bens industriais brasileiras, bem como o cálculo do risco inerente a estas atividades gerenciais. Neste sentido, foram pesquisadas empresas que estão listadas na BMF\&BOVESPA na classificação Bens Industriais, dos subsetores Comércio e Máquinas e Equipamentos, cuja população é de 16 empresas. A amostragem foi não-probabilística, onde foram selecionadas 09 (nove) empresas: Bardella, Baumer, Ind. Romi, Inepar, Kepler Weber, Lark, Metisa, Minas Máquinas e WLM. Da amostra, duas empresas possuem nível diferenciado de governança corporativa: Ind. Romi (Novo Mercado) e Inepar (Nível 1).

O método de abordagem dos resultados foi o levantamento, de modo a verificar a existência, ou não, da homogeneidade dos resultados da amostra quanto (i) à gestão do capital de giro líquido e (ii) a capacidade de geração de caixa. A coleta de dados ocorreu através da obtenção dos relatórios Balanço Patrimonial e Demonstração do Resultado do Exercício. Vale salientar que apenas a Minas Máquinas não apresentou website específico para estabelecer um canal adicional com o público interessado.

Para cada empresa foram coletados 47 relatórios trimestrais, entre março de 1999 a setembro de 2010. Uma vez coletados os dados, estes foram estruturados da seguinte forma: quanto à gestão de capital de giro líquido, estes seguiram as orientações de classificação de Fleuriet, Kehdy e Blanc (2003), onde está exemplificado no Quadro 3. Uma vez classificados e, de acordo com os resultados obtidos para as variáveis CCL, NIG e ST, cada trimestre foi categorizado e pontuado conforme o Quadro 1. Quanto ao fluxo de caixa, estes foram formatados de acordo com o modelo proposto no Quadro 2.

\begin{tabular}{|c|c|c|c|}
\hline Tipo & Ativo Circulante & Tipo & Passivo Circulante \\
\hline F & Disponibilidades & F & Empréstimos e financiamentos \\
\multicolumn{2}{|c|}{ R. Cont. Ufba, Salvador-Ba, v. 7, n. 2, p. 38-51, maio-agosto 2013}
\end{tabular}




\begin{tabular}{|l|l|l|l|}
$\mathrm{O}$ & Créditos & $\mathrm{F}$ & Debêntures \\
$\mathrm{O}$ & Estoques & $\mathrm{F}$ & Dividendos a pagar \\
$\mathrm{O}$ & Outros & $\mathrm{F}$ & Dívidas com pessoas ligadas \\
& & $\mathrm{O}$ & Fornecedores \\
& & $\mathrm{O}$ & Impostos, taxas e contribuições \\
& & $\mathrm{O}$ & Provisões \\
& & $\mathrm{O}$ & Outros \\
\hline
\end{tabular}

Quadro 3 - Classificação das contas circulantes para as empresas de bens industriais Nota: $\mathrm{F}$ = financeiro; $\mathrm{O}=$ operacional

Fonte: Elaboração Própria.

A análise dos dados aconteceu em duas etapas. Para a gestão do capital de giro líquido, foi realizada uma distribuição de freqüência absoluta para as estruturas de capital de giro líquido encontradas nas empresas, com suas respectivas notas médias, calculadas e classificadas de acordo com o modelo mostrado no Quadro 1. Para testar se há diferença significativa entre as notas das empresas estudadas, foi utilizado o teste não-paramétrico Kruskal-Wallis, ao nível de $5 \%$ de significância.

Uma vez calculadas as notas para a gestão de capital de giro líquido, foi realizado um teste de aderência para verificar a maneira pela qual elas estão distribuídas, de maneira agregada. A escolha do modelo probabilístico aconteceu com base nos resultados da estatística de ajuste de distribuição Qui-Quadrado, que é definido pelas seguintes hipóteses: $H_{0}$ - os dados seguem a distribuição especificada; $H_{1}$ - os dados não seguem a distribuição especificada. Os valores do teste Qui-Quadrado são mostrados na variável Goodness-of-Fit (GoF), bem como tal modelo de distribuição é testado ao nível de significância de $1 \%$. Uma vez encontrada a curva de distribuição probabilística para a série histórica das notas, foi calculada, via a simulação de 50.000 valores pela técnica de Monte Carlo, a probabilidade agregada das empresas estarem em uma situação de solvência (estruturas I e II), de inadimplência (estruturas III e IV) ou de insolvência (estruturas V e VI).

Por último, um aspecto analisado foi a mensuração da importância da variação $(\Delta)$ das variáveis PELP, PL, ARLP, AP, Receita Bruta (RB), CF na variação $(\Delta)$ de $S T$, de modo a determinar quem de fato influencia nas suas oscilações. Para isto, foi realizada uma regressão linear conforme mostra a seguinte equação 1 :

$\triangle S T=$ Constante $+\beta_{1} * \triangle P E L P+\beta_{2} * \Delta P L-\beta_{3} * \triangle A R L P-\beta_{4} * \Delta A P-\beta_{5} * \Delta R B-\beta_{6} * \Delta C F .(\mathbf{1})$

Em relação à capacidade de geração de caixa, também foi realizada a estatística descritiva para as variáveis FCO, FCI, FCF e FC ponderadas pelo seu Ativo Total, bem como a realização do teste Kruskal-Wallis $(K W)$, também a $5 \%$ de significância, para verificar se há diferenças significativas entre os valores dos fluxos de caixa das empresas. Foi realizado o teste de aderência para as citadas variáveis e a capacidade de geração de caixa foi medida a partir do cálculo da probabilidade destes serem maiores que zero $(\mathrm{p}>0)$ pela simulação de 50.000 valores com a técnica de Monte Carlo, utilizando o software Crystall Ball.

\section{ANÁLISE E DISCUSSÃO DOS RESULTADOS}

\subsection{Gestão do capital de giro líquido}

A Tabela 1 mostra os resultados da classificação dos trimestres de cada empresa quanto à gestão do capital de giro líquido. Os valores dentro dos colchetes indicam a nota média da categoria, enquanto que os fora dos colchetes representam a freqüência obtida na estrutura.

TABELA 1 - Classificação e notas para a gestão do capital de giro líquido (1999-2010) 


\begin{tabular}{c|l|c|c|c|c|c|c|c}
\hline Grupo & Empresa & Péssima & $\begin{array}{c}\text { Muito } \\
\text { Ruim }\end{array}$ & Insatisfatória & $\begin{array}{c}\text { Alto } \\
\text { Risco }\end{array}$ & Sólida & Excelente & $\begin{array}{c}\text { Nota } \\
\text { Média }\end{array}$ \\
\hline \multirow{3}{*}{1} & Inepar & $24[0,52]$ & $18[2,57]$ & $05[4,16]$ & - & - & - & 1,69 \\
& K. Weber & $29[1,31]$ & $03[2,48]$ & $10[4,25]$ & - & $04[7,42]$ & $01[8,33]$ & 2,68 \\
& Lark & $25[080]$ & $05[2,57]$ & $10[4,24]$ & - & $07[7,49]$ & - & 2,72 \\
\hline \hline \multirow{6}{*}{2} & WLM & $18[0,86]$ & - & $04[4,43]$ & - & $25[7,39]$ & - & 4,64 \\
& Bardella & - & - & $41[4,72]$ & - & $06[7,29]$ & - & 5,05 \\
& Minas Maq. & - & - & $39[4,70]$ & - & $08[7,16]$ & - & 5,12 \\
& Baumer & - & - & $30[4,49]$ & - & $17[7,29]$ & - & 5,51 \\
& Metisa & - & - & $22[4,38]$ & - & $25[6,97]$ & - & 5,76 \\
& Ind. Romi & - & - & $25[4,39]$ & - & $22[7,40]$ & - & 5,80 \\
\hline
\end{tabular}

Fonte: Elaboração Própria.

A metodologia proposta no Quadro 1 permite que o desempenho de cada empresa seja mensurado de acordo com a sua respectiva classificação e, através de uma escala pré-definida (0 a 10), torna-se possível realizar comparações entre as suas performances. Inicialmente foi realizado Teste de Normalidade Komolgorov-Sminov em conjunto com o Teste de homogeneidade de variâncias, no intuito de se descobrir a viabilidade do uso de testes paramétricos. Os resultados indicaram que a distribuição das notas de todas as empresas da amostra não é Normal ( $p$-values < 1\%) e que suas variâncias não são homogêneas (Levene Test $p$-value $=0,000$ ), apontando para o uso de técnicas não-paramétricas de comparações de grupos. Assim, foi utilizado o teste Kruskal - Wallis $(K W)$ para identificar se as notas das empresas são estatisticamente semelhantes (i.e., se vêm da mesma população), cujo valor indicou a existência de heterogeneidade entre as notas das empresas ( $K W$ p-value $=0,000)$.

Ao observar a distribuição das notas médias na Tabela 1, foram identificados dois grupos. Para testar a homogeneidade destes grupos, foi aplicado novamente o teste $K W$, onde foi verificada a homogeneidade destes (Grupo 1 p-value $=0,070$; Grupo 2 p-value $=0,486$ ), ou seja, as notas médias obtidas vêm de uma mesma população. No Grupo 1, percebe-se que a maioria dos resultados é do tipo Péssimo, mostrando assim a ineficiência e ineficácia que estas empresas possuem quanto à gestão do seu capital de giro líquido. Quanto ao Grupo 2, nota-se que a maioria dos resultados é do tipo Insatisfatório, ou seja, ainda que elas sejam eficazes, elas são ineficientes quanto à gestão destes recursos no curto prazo.

No intuito de poder apresentar uma medida de risco associada ao gerenciamento do capital de giro líquido de empresas de bens industriais, foi estimada a probabilidade delas estarem em uma situação de solvência (estruturas I e II), de inadimplência (estruturas III e IV) ou de insolvência (estruturas V e VI). A Tabela 2 mostra os resultados do teste de aderência QuiQuadrado aplicado às notas de gestão de capital de giro líquido, de maneira agregada.

TABELA 2 - Teste de aderência e probabilidades de risco do capital de giro líquido (*Sig. 1\%)

\begin{tabular}{l|r|c|c|c}
\hline \multicolumn{1}{c|}{ Empresas Agregadas } & Nota CG & p Insolvente & p Inadimplente & p Solvente \\
\hline GoF & 350,1277 & & & \\
p-value & $0,000^{*}$ & $32,25 \%$ & $51,16 \%$ & $16,58 \%$ \\
Tipo & Weibull & & & \\
\hline
\end{tabular}

Fonte: Elaboração Própria.

Sobre os resultados das empresas agregadas, o teste de aderência indicou que, dentre as curvas de distribuição de probabilidade conhecidas, a que melhor se adaptou, pelo critério do Qui-Quadrado foi a distribuição Weibull, ainda que $H_{0}$ tenha sido rejeitada. Isto pode ter acontecido por causa da quase ausência de notas observadas nas categorias "Alto Risco" e "Excelente", comprometendo assim o ajuste da distribuição. Supondo que os dados das notas de capital de giro líquido da destas empresas seguissem uma distribuição Weibull e, após 
simular 50.000 valores pela técnica de Monte Carlo, verificou-se que as chances destas estarem Solventes (i.e. ser eficiente e eficaz na gestão do capital de giro líquido) são de, aproximadamente, $\mathbf{1 7 \%}$. Já as chances delas estarem Inadimplentes (i.e eficiente e ineficaz ou ineficiente e eficaz na gestão do capital de giro líquido) são de $\mathbf{5 1 \%}$, enquanto que as chances de estarem Insolventes (i.e. ineficaz e ineficiente na gestão do capital de giro líquido) são de 32\%. Assim, se confirmada tal hipótese, verifica-se que tais empresas analisadas tendem a apresentar dificuldades no gerenciamento do seu capital de giro líquido, haja vista que, em grande parte dos casos, ele será insuficiente para atender seu ciclo financeiro.

A seguir, a Tabela 3 mostra os resultados da regressão linear para verificar a importância da oscilação das variáveis preditoras na variação do ST. Neste quesito, é importante mencionar que não foi calculado a regressão para a Inepar, dado que as variáveis explicativas não apresentaram nenhuma relação com a variável dependente. Para as demais empresas, estas atenderam aos pressupostos de representatividade da equação, de multicolinearidade aceitável das variáveis preditoras, de ausência de autocorrelação serial e da normalidade e homocedasticidade dos resíduos, conforme ensinam Cunha e Coelho (2009).

TABELA 3 - Coeficientes de regressão para a estimação de $\Delta \mathrm{ST}(\Delta$ em $\mathrm{R} \$$ mil) $(* \operatorname{Sig} .5 \%)$.

\begin{tabular}{|c|c|c|c|c|c|c|c|c|}
\hline$\Delta \mathrm{ST}$ & Constante & $\Delta$ PELP & $\Delta \mathbf{P L}$ & $\triangle A R L P$ & $\Delta \mathbf{A P}$ & $\Delta \mathbf{R B}$ & $\Delta \mathbf{C F}$ & $\mathbf{R}^{2}$ Ajust. \\
\hline Bardella & $-212,05$ & 0,89 & 0,71 & $-1,21$ & $=$ & $=$ & - & 0,655 \\
\hline $\mathrm{P}$ & 0,908 & $0,000^{*}$ & $0,003^{*}$ & $0,041^{*}$ & - & - & - & \\
\hline Baumer & $-287,59$ & 1,67 & 0,47 & - & - & $-0,18$ & 38,56 & 0,459 \\
\hline $\mathrm{P}$ & 0,163 & $0,000^{*}$ & $0,011^{*}$ & - & - & $0,001^{*}$ & $0,001^{*}$ & \\
\hline K.Weber & $-1.642,35$ & 0,90 & 1,02 & $-0,81$ & $-0,67$ & $-0,31$ & $-42,11$ & 0,982 \\
\hline $\mathrm{P}$ & 0,120 & $0,000^{*}$ & $0,000^{*}$ & $0,000^{*}$ & $0,000^{*}$ & $0,012^{*}$ & $0,000^{*}$ & \\
\hline Lark & $-241,33$ & 1,03 & 0,79 & $-0,96$ & $-0,92$ & - & $-88,54$ & 0,933 \\
\hline $\mathrm{P}$ & $0,003^{*}$ & $0,000^{*}$ & $0,000^{*}$ & $0,000^{*}$ & $0,000^{*}$ & - & $0,000^{*}$ & \\
\hline Metisa & $-1.652,18$ & 0,97 & 1,13 & - & - & $-0,25$ & $-289,63$ & 0,818 \\
\hline $\mathrm{P}$ & $0,035^{*}$ & $0,000^{*}$ & $0,000^{*}$ & - & - & $0,005^{*}$ & $0,000^{*}$ & \\
\hline M.Maq. & 29,49 & - & - & - & - & $-0,31$ & $-228,77$ & 0,767 \\
\hline $\mathrm{P}$ & 0,919 & - & - & - & - & $0,000^{*}$ & $0,000^{*}$ & \\
\hline Romi & $-4.884,93$ & 1,02 & 1,02 & $-1,54$ & $-0,89$ & - & $-167,67$ & 0,974 \\
\hline $\mathrm{P}$ & $0,005^{*}$ & $0,000^{*}$ & $0,000^{*}$ & $0,000^{*}$ & $0,000^{*}$ & - & $0,000^{*}$ & \\
\hline WLM & $-1.044,01$ & 1,00 & 1,02 & $-1,29$ & $-0,95$ & $-0,04$ & $-1.161,33$ & 0,992 \\
\hline $\mathrm{P}$ & $0,044^{*}$ & $0,000^{*}$ & $0,000^{*}$ & $0,000^{*}$ & $0,000^{*}$ & $0,001^{*}$ & $0,000^{*}$ & \\
\hline
\end{tabular}

Fonte: Elaboração Própria.

Os resultados na Tabela 3 mostram que, em sua maioria, o ST aumenta quando ocorrem variações positivas no PELP e no PL. Tal informação vem a confirmar a natureza destas contas, que são as suas principais fontes de financiamento de longo prazo. O detalhe é observar quais são as outras contas que, de fato, concorrem com o ST pela demanda destes recursos monetários. Em termos de contas de investimento a longo prazo, na maioria das empresas, o ARLP é uma das variáveis que concorrem diretamente com o ST, principalmente porque nela estão os valores das vendas a receber superiores a 01 (um) ano. Isto pode denotar que (a) créditos de curto prazo estejam virando de longo prazo por dificuldades de cobrança ou (b) a empresa está financiando seus clientes com crédito próprio, haja vista que elas vendem bens de capital de alto valor agregado. Em seguida vem o AP, indicando que qualquer expansão de seu ativo imobilizado (principal conta contábil) consumirá recursos monetários que seriam destinados a financiar o saldo em tesouraria.

Em termos de contas de resultado operacional, o ciclo financeiro é uma importante variável a ser considerada na gestão do Saldo em Tesouraria destas empresas. Vieira (2005, p.124) explica que crescimentos expressivos do ciclo financeiro provocam pressões na estrutura financeira das empresas por causa do aumento significativo da NIG sem o devido 
acompanhamento do aumento do CCL. Por exemplo, a WLM: para cada 01 (um) dia a mais no seu ciclo financeiro, o saldo em tesouraria diminui em $\mathrm{R} \$ 1.161,33$ mil, e vice- versa. Por outro lado, a variação da receita bruta também afeta o desempenho do saldo em tesouraria da maioria das empresas aqui estudadas, ainda que em uma menor proporção. Vieira (2005, p.123) explana que o crescimento muito elevado das vendas causa um aumento significativo na NIG mesmo sem a variação no ciclo financeiro. Se a variação do CCL não acompanhar tal aumento, a NIG passará a drenar recursos monetários do saldo em tesouraria.

Por fim, é interessante observar os resultados apresentados pela Minas Máquinas. A variação de seu saldo em tesouraria é explicada tão somente pelas variações da receita bruta e do ciclo financeiro, as quais em conjunto respondem por quase $77 \%$ destas oscilações. É o único caso aqui observado em que os ativos de longo prazo não concorrem com o ST por recursos de longo prazo. Seu problema pode estar na política de vendas ao consumidor adotada, que a compele a ter um ciclo financeiro inadequado para a sua atividade operacional.

\subsection{Gestão do fluxo de caixa}

A Tabela 4 mostra os resultados da estatística descritiva para as empresas de bens industriais quanto à gestão do fluxo de caixa. Neste caso, como as empresas apresentaram, majoritariamente, elevados coeficientes de variação (acima de 100\%) nestas variáveis, optouse por apresentar na tabela, além das médias, os valores das medianas, principalmente porque os testes não-paramétricos de agrupamento são baseados nela. Ademais, os valores dos fluxos de caixa foram padronizados para efeito de comparação, dividindo-os pelo seu respectivo ativo total (ex: $\left.\mathrm{FCO}_{2007} / \mathrm{AT}_{2007}\right)$.

TABELA 4 - Estatística descritiva para a gestão do fluxo de caixa (1999-2010)

\begin{tabular}{c|c|r|r|r|r}
\hline Empresas & Variável & \multicolumn{1}{|c|}{ FCO/AT } & \multicolumn{1}{c|}{ FCI/AT } & \multicolumn{1}{c}{ FCF/AT } & \multicolumn{1}{c}{ FC/AT } \\
\hline \multirow{2}{*}{ Bardella } & Média & $-0,0008$ & $-0,0034$ & $-0,0046$ & $-0,0087$ \\
& Mediana & 0,0083 & $-0,0039$ & $-0,0002$ & $-0,0001$ \\
\hline \multirow{2}{*}{ Lark } & Média & $-0,0255$ & $-0,0061$ & 0,0303 & $-0,0013$ \\
& Mediana & $-0,0158$ & 0,0121 & 0,0103 & $-0,0006$ \\
\hline \multirow{2}{*}{ Minas Maq. } & Média & 0,0007 & $-0,0041$ & 0,0039 & 0,0005 \\
& Mediana & 0,0089 & $-0,0016$ & $-0,0009$ & 0,0025 \\
\hline \multirow{2}{*}{ Inepar } & Média & $-0,0096$ & $-0,0072$ & 0,0167 & $-0,0001$ \\
& Mediana & $-0,0048$ & $-0,0138$ & 0,0159 & $-0,0001$ \\
\hline \multirow{2}{*}{ K. Weber } & Média & $-0,0378$ & $-0,0085$ & 0,0438 & $-0,0025$ \\
& Mediana & $-0,0063$ & $-0,0265$ & 0,0110 & $-0,0002$ \\
\hline \multirow{2}{*}{ Baumer } & Média & 0,0059 & $-0,0055$ & 0,0020 & 0,0024 \\
& Mediana & 0,0046 & $-0,0022$ & $-0,0016$ & 0,0007 \\
\hline \multirow{2}{*}{ Ind. Romi } & Média & 0,0087 & $-0,0168$ & 0,0096 & 0,0015 \\
& Mediana & 0,0118 & $-0,0071$ & $-0,0076$ & 0,0011 \\
\hline \multirow{2}{*}{ Metisa } & Média & 0,0171 & $-0,0061$ & $-0,0027$ & 0,0083 \\
& Mediana & 0,0187 & $-0,0030$ & $-0,0077$ & 0,0121 \\
\hline \multirow{2}{*}{ WLM } & Média & 0,0103 & $-0,0021$ & $-0,0022$ & 0,0061 \\
& Mediana & 0,0015 & 0,0011 & $-0,0024$ & $-0,0009$ \\
\hline \multirow{2}{*}{ Fond }
\end{tabular}

Fonte: Elaboração Própria.

Tal como realizado anteriormente, os resultados indicaram que a distribuição dos fluxos de caixa de todas as empresas da amostra não é Normal ( $p$-values < $1 \%$ ) e que suas variâncias não são homogêneas (Levene Test p-value $=0,000$ ), apontando para o uso do teste Kruskal Wallis $(K W)$, cujos valores indicaram a existência de heterogeneidade no FCO, no FCI e no FCF $(K W$ p-values $<5 \%)$. Apenas o FC apresentou homogeneidade entre os fluxos de caixa 
$((K W$ p-value $=0,926)$, indicando que neste quesito os resultados relativos dos FC's destas vêm de uma mesma população.

Em relação ao FCO, a distribuição das medianas sugere a existência de dois grupos. O Grupo 1, formado pela Lark, Kepler Weber e Inepar, apresentou médias e medianas negativas, apontando para a dificuldade destas empresas terem fluxos de caixa operacionais positivos, principalmente pela baixa geração de lucros médios registrada no período 1998-2010: LLmédio Lark $=-\mathrm{R} \$ 501$ mil; $\mathrm{LL}_{\text {médio }} \mathrm{K}$. Weber $=-\mathrm{R} \$ 5.630$ mil e LLmédio Inepar $=-\mathrm{R} \$ 13.150 \mathrm{mil}$. O teste KW para o Grupo 1 confirma a sua homogeneidade quanto ao $\mathrm{FCO}(K W$ p-value $=$ 0,663). Já o Grupo 2, formado pelas demais, apresentou, em sua maioria, medias e medianas positivas, indicando que estas empresas conseguem ter, majoritariamente, fluxos de caixa operacionais positivos relevantes, por causa da elevada geração de lucros médios registrados entre 1999 e 2010. O teste KW para o Grupo 2 também confirma a sua homogeneidade quanto ao $\mathrm{FCO}(K W$ p-value $=0,263)$.

A respeito do FCI, a distribuição das medianas sugere a existência de três grupos. O Grupo 1, formado pela Kepler Weber, Inepar e Ind. Romi, apresentou as menores médias e medianas negativas. Como este é um fluxo de caixa de investimento, é interessante para as empresas que ele seja assim, pois denota para uma expansão e/ou renovação de seus ativos nãocirculantes. A Kepler Weber teve uma maior demanda média na conta investimentos (-R\$ 5.469 mil) enquanto que a Inepar e a Ind. Romi tal destinação de recursos ocorreu na conta ARLP (-R\$ 11.781 mil e -R \$ 12.017 mil, respectivamente), e o teste KW para o Grupo 1 confirma a sua homogeneidade quanto ao FCI ( $K W$ p-value $=0,309)$.

O Grupo 2, composto por Bardella, Metisa, Baumer e Minas Máquinas, também apresentou médias e medianas negativas, mas numa proporção maior que as empresas do Grupo 1. Ainda que ocorra um fluxo de investimentos para os seus ativos não-circulantes, estes são proporcionalmente menores que a do Grupo 1. Enquanto que a Bardella destina a maior parte destes recursos para a conta investimentos, as demais focam tais recursos na conta imobilizado. O teste $\mathrm{KW}$ para o Grupo 2 também confirma a sua homogeneidade quanto ao FCI ( $K W$ p-value $=0,365)$. O Grupo 3, composto por WLM e Lark, ainda que as suas médias sejam negativas, as suas medianas são positivas. Isto significa que, ao longo do período analisado, pode ter ocorrido uma política de desinvestimento nos seus ativos não-circulantes, principalmente na conta imobilizado. E o teste $\mathrm{KW}$ para o Grupo 3 confirma a sua homogeneidade quanto ao FCI ( $K W$ p-value $=0,216)$.

Sobre o FCF, a distribuição das medianas sugere a existência de dois grupos. O Grupo 1, formado por Lark, Kepler Weber e Inepar, apresentou médias e medianas positivas, Isto significa que o uso de fontes de financiamento de longo prazo é condição necessária para a formação do fluxo de caixa destas empresas, seja por via do PELP, seja pelo aumento do capital social. O teste KW para o Grupo 1 confirma a sua homogeneidade quanto ao FCF ( $K W$ $p$-value $=0,893$ ). Quando ao Grupo 2, formado pelas demais empresas, o valor de suas medianas é negativo, ou seja, ainda que elas utilizem de fontes de longo prazo para financiar seus ativos, estas o fazem numa menor frequiência que as empresas do Grupo 1. E o teste $\mathrm{KW}$ para o Grupo 2 confirma a sua homogeneidade quanto ao FCF ( $K W$ p-value $=0,846)$.

A Tabela 5 apresenta os resultados dos 50.000 valores via técnica de Monte Carlo para a probabilidade dos fluxos de caixa das empresas serem maiores que zero, bem como o formato da distribuição de probabilidades que melhor se ajustou ao comportamento dos dados coletados. Tal simulação visa apresentar uma medida de risco associada à gestão dos fluxos de caixa, de modo compreender melhor o seu comportamento ao longo do tempo.

TABELA 5 - Distribuição e probabilidades dos FC's $>0$ para as empresas estudadas (*Sig. 1\%).

\begin{tabular}{l|c|c|c|c}
\hline Probabilidade FC's $>0$ & FCO & FCI & FCF & FC \\
\hline Bardella & $\mathbf{5 2 , 0 3 \%}$ & $\mathbf{2 3 , 8 6 \%}$ & $\mathbf{4 5 , 3 2 \%}$ & $\mathbf{2 3 , 4 0 \%}$ \\
\hline
\end{tabular}

R. Cont. Ufba, Salvador-Ba, v. 7, n. 2, p. 38-51, maio-agosto 2013 


\begin{tabular}{l|c|c|c|c} 
Tipo & T student & T student & Logística & T student \\
\hline Baumer & $\mathbf{5 6 , 8 6 \%}$ & $\mathbf{3 0 , 2 5 \%}$ & $\mathbf{4 8 , 5 5 \%}$ & $\mathbf{5 0 , 1 4 \%}$ \\
Tipo & Logística & Extremo Mínimo & Lognormal & Lognormal \\
\hline Ind. Romi & $\mathbf{5 8 , 7 2 \%}$ & $\mathbf{2 8 , 4 3 \%}$ & $\mathbf{5 2 , 6 2 \%}$ & $\mathbf{5 2 , 1 0 \%}$ \\
Tipo & T student & Extremo Mínimo & Lognormal & T student \\
\hline Inepar & $\mathbf{4 2 , 6 0 \%}$ & $\mathbf{3 6 , 1 1 \%}$ & $\mathbf{6 3 , 9 9 \%}$ & $\mathbf{4 9 , 6 3 \%}$ \\
Tipo & Logística & Logística & Logística & T Student \\
\hline Kepler Weber & $\mathbf{3 4 , 2 9 \%}$ & $\mathbf{2 9 , 6 4 \%}$ & $\mathbf{7 6 , 4 1 \%}$ & $\mathbf{5 1 , 0 7 \%}$ \\
Tipo & T student & T student & T student & T student \\
\hline Lark & $\mathbf{3 8 , 9 7 \%}$ & $\mathbf{5 0 , 3 9 \%}$ & $\mathbf{6 0 , 8 3 \%}$ & $\mathbf{4 8 , 4 1 \%}$ \\
Tipo & Logística & Weibull & Logística & Logística \\
\hline Metisa & $\mathbf{6 2 , 2 2 \%}$ & $\mathbf{3 1 , 1 5 \%}$ & $\mathbf{5 1 , 5 2 \%}$ & $\mathbf{6 6 , 0 3 \%}$ \\
Tipo & Extremo Máximo & Extremo Mínimo & T student & T student \\
\hline Minas Máquinas & $\mathbf{4 8 , 6 3 \%}$ & $\mathbf{2 9 , 1 0 \%}$ & $\mathbf{5 5 , 6 6 \%}$ & $\mathbf{4 4 , 9 7 \%}$ \\
Tipo & Logística & T student & T student & Weibull \\
\hline WLM & $\mathbf{4 5 , 9 4 \%}$ & $\mathbf{3 8 , 5 4 \%}$ & $\mathbf{3 5 , 9 6 \%}$ & $\mathbf{6 6 , 2 9 \%}$ \\
Tipo & Lognormal & T student & T student & T student \\
\hline
\end{tabular}

Fonte: Elaboração Própria.

Sobre o desempenho dos testes de ajustamento de distribuição, é importante mencionar que $H_{0}$ não foi rejeitada em $2 / 3$ dos fluxos de caixa calculados. Para o $1 / 3$ restante, neste estudo, será admitido o pressuposto de que os dados seguem tal distribuição, de modo a contribuir com alguma medida de risco a partir da melhor função de densidade de probabilidade encontrada para estes fluxos de caixa.

Em relação ao FCO, somente quatro empresas excederam a expectativa de $50 \%$ de chances de apresentarem valores positivos, enquanto que cinco empresas não conseguiu alcançar tal patamar. Sobre o FCI, apenas uma empresa excedeu a expectativa de $50 \%$ de chances de ter valores positivos, enquanto que as demais oito empresas apresentaram probabilidades dentro do esperado. Quanto ao FCF, seis empresas excederam a expectativa de valores positivos enquanto que três empresas ficaram abaixo deste patamar. Por fim, quando ao FC, cinco empresas superaram a expectativa de $50 \%$ de chances de valores positivos, enquanto que quatro empresas ficaram abaixo desta medida.

\section{CONSIDERAÇÕES FINAIS}

O objetivo deste estudo foi avaliar o desempenho de empresas de bens industriais listadas na BMF\&BOVESPA quanto à gestão de capital de giro líquido e à gestão do fluxo de caixa, haja vista que elas estão intrinsecamente associadas e que seu bom gerenciamento é condição necessária para a manutenção da sustentabilidade financeira organizacional. Além disso, o risco inerente à gestão destas atividades deve ser considerado durante o seu planejamento, sob pena de comprometer futuras metas organizacionais.

Em relação à gestão do capital de giro líquido, foram encontrados dois grupos. No Grupo 1 três empresas encontram-se, em média, numa situação de insolvência, onde predomina a estrutura Péssima, sendo a Inepar a empresa que teve o pior desempenho, ainda que tenha nível diferenciado de governança corporativa. No Grupo 2 seis empresas estão, em média, numa situação de inadimplência, onde prevalece a estrutura Insatisfatória, sendo a Ind. Romi a empresa com o melhor resultado. De maneira agregada e admitindo a hipótese de distribuição Weibull, tais empresas tem $32 \%$ de chances de ficaram insolventes, $51 \%$ de estarem inadimplentes e $17 \%$ de estarem solventes.

Uma vez calculadas as equações de regressão, foi percebido que os overtradings observados nas séries históricas das empresas sejam causados pela combinação de (1) excesso de investimentos ligados à escassez de recursos próprios ou de terceiros de longo prazo com (2) elevados ciclos financeiros e crescimento das vendas, em alguns casos, (3) uma baixa geração 
de lucros ou prejuízo nas operações. Assim, é importante para seus gestores reverem suas estratégias organizacionais, de modo que contemplem soluções para tais contratempos financeiros.

Quanto à gestão do fluxo de caixa, embora a maioria das empresas estudadas tenham superado a expectativa de $50 \%$ de chances de ter valores positivos (cinco casos), também é importante ressaltar o elevado risco de não-ocorrência destes, cujos valores estão oscilando entre $34 \%$ e $50 \%$. Por outro lado, exceder tal expectativa de fluxos de caixa positivos não significa que tais valores sejam suficientes para financiar as suas demandas de curto e longo prazo. Neste sentido, é interessante para os gestores calcularem a probabilidade de se obter os fluxos de caixa mínimos necessários para o financiamento dos ativos das companhias, com o intuito de também incrementar seu Fair Value perante o mercado financeiro.

Dessa maneira, este estudo procurou contribuir, de maneira preliminar, com a apresentação de algumas metodologias para se aferir a qualidade e o risco inerente à gestão do capital de giro líquido e do fluxo de caixa de empresas de bens industriais brasileiras, haja vista que é um setor primordial para a economia do país, e com grandes oportunidades de estudos a serem feitos. Como continuação do estudo, é sugerida a ampliação do estudo para as demais empresas deste agrupamento, de modo a compreender melhor o desempenho da gestão do capital de giro líquido e do fluxo de caixa em risco do setor, bem como a inclusão de variáveis macroeconômicas nestas análises, de modo que melhorias específicas para esta atividade industrial sejam desenvolvidas, com o objetivo principal da sustentabilidade financeira.

\section{REFERÊNCIAS}

ALBUQUERQUE, A. R. A; PEROBELLI, F. F. C; CASTRO, R. S. Fluxo de caixa em risco: uma nova abordagem para o setor de distribuição elétrica. In: IX Encontro Brasileiro de Finanças, São Leopoldo, Anais... São Paulo: SBFIN, 2009.

ASSAF NETO, A.; SILVA, C. A. T. Administração do capital de giro. 3. ed. São Paulo: Atlas, 2002.

Associação Brasileira Da Indústria De Máquina E Equipamentos. A indústria brasileira de bens de capital ainda tem muito trabalho pela frente. Informativo mensal informaq, n. 109, fev. 2008. Disponível em: http://www.abimaq.org.br. Acesso em: 01/08/2008. Apresentação dos indicadores conjunturais - anos anteriores. Disponível em: http://www.abimaq.org.br. Acesso em: 18/04/2010.

BRASIL, H. V.; BRASIL, H. G. Gestão financeira das empresas: um modelo dinâmico. 3. ed. Rio de Janeiro: Qualitymark, 1997.

BRIGHAM, E. F.; HOUSTON, J. F. Fundamentos da moderna administração financeira. Rio de Janeiro: Campus, 1999.

CUNHA, J. V. A.; COELHO, A. C. Regressão linear múltipla. In: CORRAR, L. J.; PAULO, E.; DIAS FILHO, J. M. (Orgs.). Análise multivariada para os cursos de Administração, Ciências Contábeis e Economia. 1. ed. São Paulo: Atlas, 2009.

FAMÁ, R.; GRAVA, J. W. Liquidez e a teoria dos elementos causadores de insolvência. Caderno de Pesquisa em Administração, São Paulo, v.1, n. 12, 2. trimestre, 2000.

FLEURIET, M.; KEHDY, R.; BLANC, G. O Modelo Fleuriet: A dinâmica financeira das empresas brasileiras. Rio de Janeiro: Campus, 2003.

GITMAN, L. J. Princípios de administração financeira. 10. ed. São Paulo: Pearson, 2004.

HOJI, M. Administração financeira: uma abordagem prática. 4. ed. São Paulo: Atlas. 2004. 
MARQUES, J. A. V. C.; BRAGA, R. Análise dinâmica do capital de giro: O modelo Fleuriet. Revista de Administração de Empresas, São Paulo, v.35, n.3, p.49-63, 1995.

MOURA, H. J; MATOS, D. M. Dimensionamento do capital de giro: uma abordagem financeira. In: XXVII EnANPAD, Atibaia, Anais... Rio de Janeiro: ANPAD, 2003.

OLIVEIRA, A. M. B; SILVA, A. S; SILVA, R. N. Análise da sustentabilidade financeira sob a ótica da gestão do capital de giro e da estrutura de capital: um estudo de caso. In: XIII SIMPEP, Bauru, Anais... Bauru: SIMPEP, 2006.

OLIVEIRA, W. H. Análise financeira empreendedora. Belo Horizonte: UNA Ciências Gerenciais, 1996.

SAMANEZ, C. P. Gestão de investimentos e geração de valor. São Paulo: Pearson, 2007.

SILVA, J. P. Análise financeira das empresas. 5.ed. São Paulo: Atlas, 2001.

SOUZA, A. F. de; MENEZES, E. J. C. Estratégia, crescimento e a administração do capital de Giro. Caderno de Pesquisa em Administração, São Paulo, v.2, n. 5, 2. semestre, 1997.

THEISS JÚNIOR, F.C; WILHELM, P. P. H. Análise do capital de giro: modelo dinâmico versus modelo tradicional. In: XXIV EnANPAD, Florianópolis, Anais... Rio de Janeiro: ANPAD, 2000.

VIEIRA, M. V. Administração estratégica do capital de giro. São Paulo: Atlas, 2005. 